Science, Technology and Development 34 (1): 46-48, 2015

ISSN 0254-6418 / DOI: 10.3923/std.2015.46.48

(c) 2015 Pakistan Council for Science and Technology

\title{
Trend Analysis of Sugarcane Area and Yield in Pakistan
}

\author{
${ }^{1}$ Saira Batool, ${ }^{1}$ Nusrat Habib, ${ }^{1}$ Mubbashira Nazir, ${ }^{1}$ Sabeen Saddiqui and ${ }^{2}$ Samia Ikram \\ ${ }^{1}$ Social Sciences Research Institute, National Agricultural Research Centre, Islamabad, Pakistan \\ ${ }^{2}$ Horticultural Research Institute, National Agricultural Research Centre, Islamabad, Pakistan
}

\begin{abstract}
The present study was conducted to check the trend analysis of area and yield for sugarcane in Pakistan. The findings of the study are based on sugarcane area and yield of Pakistan by using the data from 1980-2013. Three models of trended analysis were applied but quadratic trend model was found most appropriate model for trend analysis of the present study. Forecasting was also done up to 2018 for checking the future outlook. Forecasted values are very close to actual values and have positive increasing trend in Pakistan for next upcoming 5 years (2014-18).
\end{abstract}

Key words: Trend analysis, sugarcane, area, yield, Pakistan

\section{INTRODUCTION}

Sugarcane (Saccharum officinarum) is one of the tall perennial grass of genus Saccharum inhabitant to the warm temperate of tropical regions of south Asia. Almost $80 \%$ of the world sugar is made from sugarcane for which it is considered world's largest crop (Anonymous, 2010). Sugarcane covers 28.3 million ha area for its cultivation with Brazil as a major producer followed by India, China, Pakistan, Thailand and Mexico (FAO., 2010).

Pakistan produces 55,309 metric t of sugarcane per annum according to a survey of FAO in 2011. In South Asia, Pakistan is the biggest consumers of sugar with $25.83 \mathrm{~kg}$ per capita consumption per year. In this connection, In Pakistan about 99\% of the sugar is extracted from sugarcane to meet the demand at domestic level (Azam and Mukarram, 2010). Being an agricultural country, presently Pakistan is not self sufficient in sugarcane as well as sugar production, even for domestic requirement. The present sugar shortage is being met by the import of sugar from the other countries; however, Government of Pakistan promotes sugarcane production through market support price announced prior to planting (Alam, 2007).

Sugarcane is being used in so many different ways other than sugar, like its reeds (tall and huge part of plant) used to make pens, screens, mats and thatch. In some communities of Indonesia used to eat its young unexpended inflorescence of tebu telur in raw form, steamed or toasted in various ways (Dahlia et al., 2010).

Sugarcane can be grown on different soils ranging from highly fertile and well drained. With plenty of water supply, it can be cultivated in the tropic and sub-tropic areas. It needs continuous period of more than 6-7 months of each year, depending upon either from natural rainfall or through irrigation; however, it cannot bear severe frost. Seeds and fresh stem cutting has become the most common reproduction method to grow sugarcane (Griffee, 2000).

Due to its very enormous size, the commercial sugar industry has a considerable demand for labour. The risk of unreasonable social treatment is especially high among seasonal and casual labourers. For this reason, in addition to satisfying organic standards, care should be taken to provide at least the minimum requirements for these workers, as set out in the International Federation of Organic Agriculture Movement (IFOAM) Basic Standards. The complex low-price international global market hinder these objectives considerably. The area, production and yield wise share distribution of the provinces for Sugarcane is given in Table 1.

Table 1 illustrate that Punjab province is leading in area and production of sugarcane. But the yield of sugarcane in Punjab is lowest than Sindh and Khyber Pakhtunkhwa average yield is $55800 \mathrm{t} \mathrm{ha}^{-1}$. Sindh and KPK yield is $60800 \mathrm{t} \mathrm{ha}^{-1}$ (Government of Pakistan, 2011).

Table 1: Area, production and yield of sugarcane in Pakistan

\begin{tabular}{llllll}
\hline Particular & Punjab & Sindh & KPK & Balochistan & Pakistan \\
\hline Area (\% of total) & 68.06 & 22.92 & 8.95 & 0.06 & 100 \\
Production (\% total) & 67.77 & 24.89 & 7.29 & 0.06 & 100 \\
Yield t ha $^{-1}$ & 55800 & 60800 & 60800 & 51300 & 56000 \\
\hline
\end{tabular}

Economic Survey, 2010-11

Corresponding Author: Saira Batool, Social Sciences Research Institute, National Agricultural Research Centre, Islamabad, Pakistan 
Sci. Technol. Dev., 34 (1): 46-48, 2015

The main objective of the study was to check future trends of sugarcane area and yield in Pakistan by using appropriate trend analysis model. Trend analysis studies help policy makers in taking policy decisions and farmers to shift their interests on this crop from other field crops, keeping in view the future forecast.

\section{MATERIALS AND METHODS}

The study was conducted by using time series data of sugarcane area and yield during the years 1980-2013 (33 years) of Pakistan. The data was collected from the various issues of Agriculture Statistics and Economic Surveys of Pakistan, published by Government of Pakistan (2013). Data was analyzed by using MINITAB software. The linear, exponential and quadratic these three models of trend analysis were applied for this study as these were also used by Habib et al. (2013), Karim et al. (2010), Finger (2007), Boken (2000) and Rimi et al. (2009). The best model was selected on the basis of three accuracy measures. These accuracy measures were Mean Absolute Percentage Error (MAPE), Mean Absolute Deviation (MAD) and Mean Squared Deviation (MSD). Smaller values of all these measures indicate a good fitted model with minimum forecasting errors (Karim et al., 2010). The best fitted model for this study was quadratic model and applied for forecasting the area and yield of sugarcane in Pakistan for the years 2014-18.

\section{RESULTS AND DISCUSSION}

This section deals with time series data and estimated trends in Table and Figure form of Sugarcane area and yield in Pakistan.

Selection of forecasting model for sugarcane area: The results revealed that all the values of accuracy measures are smaller in quadratic trend model (Table 2), therefore instead of other two (linear trend and exponential trend) models, quadratic trend model was selected for forecasting the future trends of sugarcane area in Pakistan on the basis of smaller values of accuracy measures (Karim et al., 2010).

Selection of forecasting model for sugarcane yield: All the values of accuracy measures for sugarcane yield in Pakistan are smaller in quadratic trend model comparative to linear trend model and exponential trend model. That's why, this study applied quadratic model to estimate the future values of sugarcane yield in Pakistan (Table 3).

Forecasted sugarcane area: After fitted the adequate model next step was to estimate forecasted values for area
Table 2: Diagnostic of model selection for sugarcane area in Pakistan

\begin{tabular}{lllc}
\hline & Criteria & & \\
& - & & \\
Measures of accuracy & MAPE & MAD & MSD \\
\hline Linear trend model & 6.08 & 58.76 & 5684.29 \\
Exponential trend model & 6.08 & 58.92 & 5733.18 \\
Quadratic trend model & 6.06 & 58.50 & 5641.11 \\
\hline
\end{tabular}

$\underline{\text { Table 3: Diagnostic of model selection for sugarcane yield in Pakistan }}$

\begin{tabular}{llll}
\hline & Criteria & & \\
& ------- \\
Measures of accuracy & MAPE & MAD & MSD \\
\hline Linear trend model & 3.55 & 1.57 & 3.64 \\
Exponential trend model & 3.49 & 1.54 & 3.69 \\
Quadratic trend model & 3.53 & 1.56 & 3.63 \\
\hline
\end{tabular}

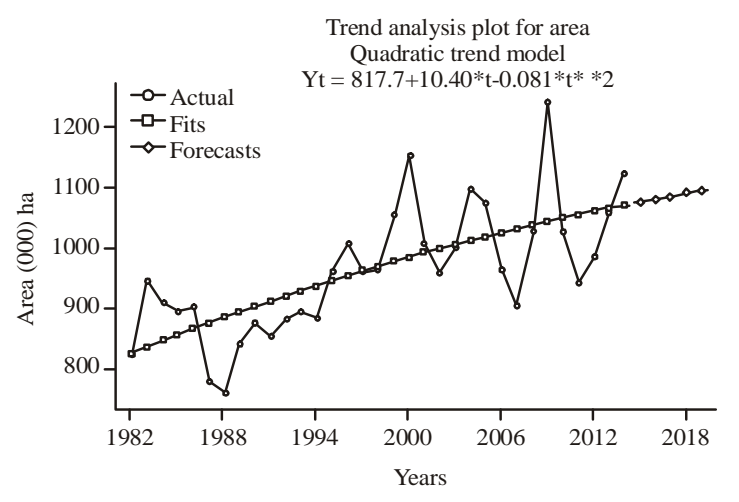

Fig. 1: Forecasted sugarcane area

and yield of sugarcane crop in Pakistan. Objective was to predict the future value subject to minimum errors as less as possible (Yaseen et al., 2005). The black, red and green symbols represents the actual, fitted and forecasted values for area at 95\% prediction interval in Pakistan (Fig. 1). Results showed that if the present growth rates of sugarcane area remain the same then the area of sugarcane in Pakistan would be 1077, 1082, 1087, 1091 and 1095 (000) ha for the years 2014-18, respectively, with continuous increasing trend (Table 4).

Forecasted sugarcane yield: The black line shows actual values, red fitted values and green line is for forecasted values of sugarcane yield at $95 \%$ prediction interval (Fig. 2). Results illustrated that if the present growth rates of sugarcane yield remain the same then yield of sugarcane in Pakistan would be 55, 55, 56, 57 and 57(000) $\mathrm{t} \mathrm{ha}^{-1}$ respectively with continuous increasing trend, for the years 2014-18, respectively (Table 4). Positive increase in yield is due to availability of high yielding varieties, proper use of inputs and in time availability of inputs for sugarcane in Pakistan. These trends show that instead of an incentive for farmers in form of high yielding from sugarcane and there is also country demand available for sugarcane in Pakistan.

The need is that to take such type of policy measures which ultimately increase the area under sugarcane in Pakistan. 


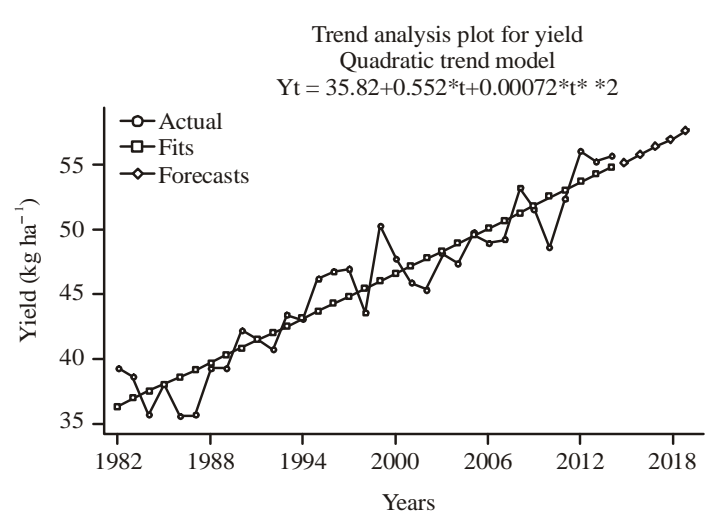

Fig. 2: Forecasted sugarcane yield

Table 4: Forecasted sugarcane area and yield

\begin{tabular}{lcc}
\hline Forecast years & Area $(000)$ ha & Yield $\left(\mathrm{t} \mathrm{ha}^{-1}\right)$ \\
\hline 2014 & 1077.57 & 55.2835 \\
2015 & 1082.38 & 55.8602 \\
2016 & 1087.02 & 56.4368 \\
2017 & 1091.50 & 57.0134 \\
2018 & 1095.81 & 57.5901 \\
\hline
\end{tabular}

Forecasted sugarcane area and yield in Pakistan: Table 4 showed that if the present growth rates of sugarcane remain the same then area of sugarcane production in Pakistan would be 1077, 1082, 1087, 1091 and 1095 (000) ha and yield would be 55, 55, 56, 57 and 57(000) t respectively for the years 2014-18 in Pakistan. Forecasted values of area and yield for sugarcane have increasing trend in coming 5 years in Pakistan. Table 4 is explaining the future trends of sugarcane area and yield in Pakistan. The results clearly revealed that there is increasing trend for area and yield of sugarcane in Pakistan.

Quadratic model provides good technique for predicting the magnitude of any variable. In this study developed model was quadratic trend model on the basis of best accuracy measures techniques. The results showed that from the forecast available by using the developed model, it can be seen that forecasted area and yield has consistent increasing trends for the coming five years from 2014-18 respectively. The increasing trend indicated that the interest of farmers to grow more and more sugarcane at their lands is due to its high returns. Being a cash and industrial crop, sugarcane is more attractive crop as compared to other filed crops (Alam and Khan, 2001). As far as the model is concerned, it can be used by researchers for forecasting of sugarcane production (area and yield) in Pakistan. However, it should be updated from time to time with inclusion of current data.

\section{REFERENCES}

Alam, S.M. and M.A. Khan, 2001. The sugar industry plays a pivotal role in the national economy of our country. Nuclear Institute of Agriculture, Tandojam, Pakistan.

Alam, S.M., 2007. Sugarcane production and sugar crisis. EconomicReview.http://findarticles.com/p/articles/ mi_hb092/is_11_38/.

Anonymous, 2010. Economic survey. Government of Pakistan, Finance Division Islamabad, Pakistan.

Azam, M. and M. Khan, 2010. Significance of the sugarcane crops with special and ference to NWFP. Sarhad J. Agric., 26: 289-295.

Boken, V.K., 2000. Forecasting spring wheat yield using time series analysis. Agron. J., 92: 1047-1053.

Dahlia, L., I. Kurniawan, D. Anggakusuma and J.M. Roshetko, 2010. Consumer preference for indigenous vegetables; Asia. World Agroforestry Centre (ICRAF) Bogor, Indonesia.

FAO., 2010. Crop production. Food and Agriculture Organization of the United Nations, Retrieved 2010-06-17.

Finger, R., 2007. Evidence of slowing yield growth the example of swiss cereal yield. Agri-Food and Agri-Environmental Economics Group, ETH Zurich, Switzerland.

Government of Pakistan, 2011. Economic survey government of Pakistan. Finance Division, Economic Advisor's Wing, Islamabad.

Government of Pakistan, 2013. Agricultural statistics of Pakistan (various issues). Ministry of Food and Agriculture, conomic Wing, Islamabad, Pakistan.

Griffee, P., 2000. Saccharum officinarum. Food and Agriculture Organization of the United Nations.

Habib, N., M.Z. Anwer, S. Siddiqui, S. Batool and S. Naheed, 2013. Trend analysis of Mungbean area and yield in Pakistan. Asian J. Agric. Rural Dev., 3: 909-913.

Karim, M.R., M.A. Awal and M. Akter, 2010. Forecasting of wheat production in Bangladesh. Bangladesh J. Agric. Res., 35: 17-28.

Rimi, R.H., S.H. Rahman, S. Karmakar and S.G. Hussain, 2009. Trend analysis of climate change and investigation on its probable impacts on rice production at Sathkhira, Bangladesh. Pak. J. Meteorol., 6: 37-50.

Yaseen, M., M. Zakriya, Islam-Ud-Din Shahzad, M.I. Khan and M.A. Javed, 2005. Modeling and forecasting the sugarcane yield of Pakistan. Int. J. Agric. Biol., 7: 180-183. 